\title{
The role of the organic farming system in the development of society
}

\author{
$S$ Kapov $^{1, *}, A$ Kojukhov ${ }^{1}, A$ Orlyansky ${ }^{1}, A$ Petenev $^{1}$, and $P$ Khaustov ${ }^{1}$ \\ ${ }^{1}$ Stavropol State Agrarian University, Zootechnichesky per., 12, Stavropol, 355017, Russia
}

\begin{abstract}
The experience of the development and use of the system of dry farming in the Stavropol Territory is considered, the causes and prerequisites for the emergence of an adaptive-landscape farming system are identified. It is shown that the farming systems of the Stavropol Territory are in constant development, they function in conditions of the joint manifestation of water and wind erosion. As a result of degradation, a third of the arable land of the region is in the zone of erosion processes. The expediency of the development of a universal soil protection system of agriculture, aimed at protecting the soil from water and wind erosion, is substantiated.
\end{abstract}

\section{Introduction}

Based on the assessment of soil fertility by Russian scientists A.T. Bolotov (1738-1833) and I.M. Komov (1750 -1792), and then A.V. Sovetov (1926-1901) introduced the term "farming systems" and gave the first definition: "The farming system is usually called various forms in which one or another way of land tenure".

Agricultural systems emerged and changed based on the conditions for the development of productive forces and depended on the level of scientific and practical progress. By its structure, they are in constant qualitative movement and development: they change, improve, are canceled, making room for other systems. At the same time, some do not stand the test of time, while others do not stand the test of new requirements. So, for example, to solve one large, complex problem of the development of society, several existing systems are combined into one, forming a larger system. Then, after some time, they can disintegrate in order to reunite at a higher demand and technological level. This process is constantly evolving and is continuous.

Each farming system has its own characteristics that emphasize its characteristic features. But at the same time, any system obeys a general definition, which is a kind of object standard: "The farming system is a complex of interrelated agrotechnical, organizational, economic, land reclamation and soil protection measures aimed at efficient use of land, increasing soil fertility in order to obtain high sustainable crop yields with the highest yield per hectare and the lowest labor costs per unit of production" $[1,2,3,4]$.

\footnotetext{
*Corresponding author: Capov-sn57@mail.ru
} 
Of course, existing farming systems have different relationships to this definition. However, the more they correspond to it, the more effective and long-term their use in production.

Each of the existing farming systems can be attributed to one of the types that solve different problems $[5,6,7,8]$.

$>$ primitive - are aimed at restoring soil fertility in a natural way and include such systems as: slash-and-burn, forest, fallow, etc.;

extensive - are aimed at partial restoration of soil fertility by applying manure, sowing perennial grasses, introducing steam into the crop rotation, liming and include such systems as: three-field (fallow, winter and spring), multi-field grass, tilled, fallow, grainfallen, soil -protective, etc.;

$>$ transitional - are aimed at the human impact on soil fertility through the use of organic and mineral fertilizers, pesticides, reclamation and include such as: alternative farming systems (biodynamic (R. Steiner), biological (M. Fukuoka and A. Howard), organic (International Organic Farming Association FQOAM), etc.;

intense - aimed at the comprehensive use of mechanization and automation, land reclamation, breeding, genetic bioengineering, GM varieties and include such as: precision farming system; savings farming system; dry farming system; adaptive landscape farming system, etc.

\section{Materials and methods}

Any of the listed farming systems is a kind of farming model in certain boundary conditions and in accordance with the goals and ideas of its authors. Unfortunately, for the most part, such models do not have a mathematical interpretation. This does not allow, in spite of the richest research and life experience that fills the systems, to create a comprehensive farming model, in which each of the existing farming systems would be its particular case with a certain combination of initial conditions and taking into account the acting factors. Such an approach would make it possible to efficiently manage the farming system, taking into account its features, depending on the conditions and circumstances, in advance, in advance, and therefore with the greatest effect.

Thus, the farming system should not change after years from the beginning of its use, when the amount of contraindications for its use reaches a critical mass, but immediately. Such a changing system should be more flexible, adapt to any expected, rather than accomplished, natural manifestations and always ensure the maximum effect of use. It is clear that the achievement of such a level is a matter of the near future, and the ongoing scientific research can become the starting material for the formation of a comprehensive model of the farming system.

An objective confirmation and example of using the farming system model is the emergence and development of the dry farming system in the Stavropol Territory. The reasons and prerequisites for the emergence of the dry farming system were the bleak prospects for the development of agriculture in the region. Back in the late sixties of the last century, it became obvious that the arid climate, the growing manifestation of soil erosion processes and outdated field cultivation technologies are becoming an insurmountable obstacle to the dynamic development of agriculture in the region. The annual gross grain harvest did not grow, the costs of their production increased markedly, and in the plans of the state, the Stavropol Territory has always been considered as one of the country's granaries. Therefore, overcoming the crisis in agriculture in the Stavropol Territory was recognized as a state matter, and the Stavropol Research Institute of Agriculture (SNIISKh) was instructed to prepare a plan of measures for its implementation. The in-depth analysis of the data set carried out by the Institute led to the conclusion that the task can be 
successfully implemented only with a systematic approach to the solution, built on the basis of the principle of strict zoning of territories. In a short time, the systems of fallows, zonal crop rotation, soil protection measures, levels of intensification of agriculture and varietal policy in crop production were scientifically substantiated. All this was combined in a balanced way into a single model of interconnected actions., named Dry farming system of Stavropol Region. The system received serious administrative support, namely, at the time of its widespread implementation, it was recommended to engage in economic activities on the land only within the framework of the dry farming system. In addition, the developed system had substantiated state support: for example, by 1984, the volume of applied mineral fertilizers reached the value of 408 thousand tons of active ingredient.

The result of its use was that by the end of the five-year period, the agriculture of the region reached the level of crop production resistant to climatic fluctuations and received a consistently high yield of grain crops. Therefore, the system quickly gained indisputable prestige as an integrated, effective tool for farming in difficult soil and climatic conditions. This was almost the first case of an organized unification of several farming systems into one large system, subordinated to a single strategic task of the development of society. An effective approach to the organization of such farming has become widespread. So, both district systems of agriculture (for example, Ipatovskaya, Shpakovskaya Kirovskaya and others) were developed and successfully implemented, as well as for several problem areas of the country, taking into account not only the proven principles of a systematic approach, but also the features of possible risks inherent in this region. Such an example is the developed methodological and methodological recommendations for the systemic and complex solution of the problems of the agro-industrial complex of the Volgograd Region.

However, in the early nineties, the use and spread of the farming system stopped. This period saw deep state upheavals. The collapse of the USSR was followed by a change in the form of ownership of the means of production and the abandonment of the planned system of organizing the economy in favor of a market one. To overcome the transition period, the government of the Russian Federation applied the most severe form of economic reforms, which included the rejection of financial state support for agriculture, the destruction of the price parity between the resources consumed by the agro-industrial complex and agricultural products, as well as the purchase of food abroad. Deprived of state support, agricultural enterprises, in an effort to stay on the surface of business, got rid of costly industries, excluded activities that brought income delayed in time or did not provide for it at all. One by one, important elements were excluded from the dry farming system: soilregenerating crops (mainly perennial grasses and legumes); clean couples, couple care operations, conservation measures, etc. The share of commercial crops, usually row crops (sunflower, sugar beet), has unreasonably increased. As a result, skewed crop rotations violated the optimal timing of field work and thus only exacerbated losses. Since the dry farming system, as noted, was a balanced community of many interrelated factors, the exclusion of several of them led to the loss of the entire system and the systemic approach in general. In addition, over recent years, the balance of humus and nutrients has become negative, and the proportion of soils subject to wind and water erosion has increased.

\section{Scientific results}

Now, they are trying to fill the vacant space in the region with foreign technologies. Most of them are based on minimal human impact on the soil and look very appropriate in regions of risky farming. Such technologies involved are No-Till, Mini-Till, Strip-Till and other Direct Seeding technologies that form the basis of Zero Till. In the world, about $6.8 \%$ of arable land is cultivated with the zero-technology system. For example, the No-Till technology is widely used in the United States and is designed to treat soils prone to wind 
erosion, and in Canada - to retain moisture in arid regions. The experience of use shows that there is a paradox, if $90-95 \%$ of all used areas are cultivated with this technology in Brazil, Argentina, Paraguay and Australia, then on the European continent - only 3\% of arable land $[5,6,7,8,14,15]$.

This means that there is a problem: it is impossible to transfer zero technology routinely and transfer it to a certain area without proper scientific and experimental justification. In the case of Russia, although the ad hoc and sketchy use of zero technology is an effective and rewarding experience, it is not enough. Thus, a number of serious shortcomings have been identified: weediness of crops, the development of water erosion, the appearance and preservation of sources of infections and pests, the use of seeding complexes with special openers, an overestimated seeding rate, etc. Therefore, a scientifically based approach to the use of zero technology is required.

After 2010, the need and the possibility of returning to systemic approaches in agriculture became obvious. It would be irrational to fully use the already proven system of dry farming in the Stavro-Polish Territory: significant changes in the organization of the agro-industrial complex and changes in the state of agriculture required the restructuring and modernization of the dry farming system. Therefore, in 2013 SNIISKh reported on the completion of a large work on the creation of a new system. It received the following name and definition: an adaptive-landscape farming system is a system of land use of a certain ecological group, focused on the production of products of economically and environmentally determined quantity and quality in accordance with social (market) needs, natural and production resources, ensuring the sustainability of the agricultural landscape and soil fertility $[9,10,11]$.

This system implies adaptation taking into account not only natural, but also production factors. In addition, almost the same information and methodological tasks have been solved as when creating a dry farming system, but on the basis of a real data array and more modern information and methodological tools. This emphasizes the continuity of farming systems, but already separated by the achieved levels of development.

New, modern, really significant element of the developed system is adaptive landscape land management, which is based on geographically coordinated land assessment indicators. This dramatically increases the concreteness and accuracy of assessing their condition, and hence the effectiveness of proposals and solutions of the system.

Along with this, the adaptive landscape farming system leaves room for work on its improvement. This is not a fault or miscalculation by the compilers. As of today, effective solutions to some problems have not yet been found. For example, the system recognizes that, despite effective measures, about a third of the arable land in the province is degraded land as a result of wind and water erosion [12] (Figure 1).

This is natural, since almost all lands (more than 95\%) of the Stavropol Region have a low humus content and are subject to water and wind erosion. The reason is the geographic location of the region, its relief and the nature of precipitation. It was found that about $3 / 4$ of the farmland area is located on slopes exceeding $2.5^{\circ}-3.0^{\circ}$, and $2 / 3$ of precipitation falls in the form of 5-7 high-intensity showers (more than $0.5 \mathrm{~mm} / \mathrm{min}$.) [13]. This combination of soil and climatic factors is erosion-prone, since it does not ensure the absorption of precipitation by the soil, which causes surface runoff and soil washout. The lack of soil protection measures and rational organization of the territory inevitably ends with the development of erosion processes and serious losses.

The climatic features of the region also include the fact that meteorologists consider it a "windy" region: the average annual duration of winds is more than $10 \mathrm{~m} / \mathrm{s}$ (capable of lifting particles of unprotected soil into the air) practically anywhere in the Stavropol Territory for at least 32 days. Winds with a speed of $25-28 \mathrm{~m} / \mathrm{s}$ are observed at least twice a year. Hurricanes with a speed of more than $40 \mathrm{~m} / \mathrm{s}$ are periodically noted. 


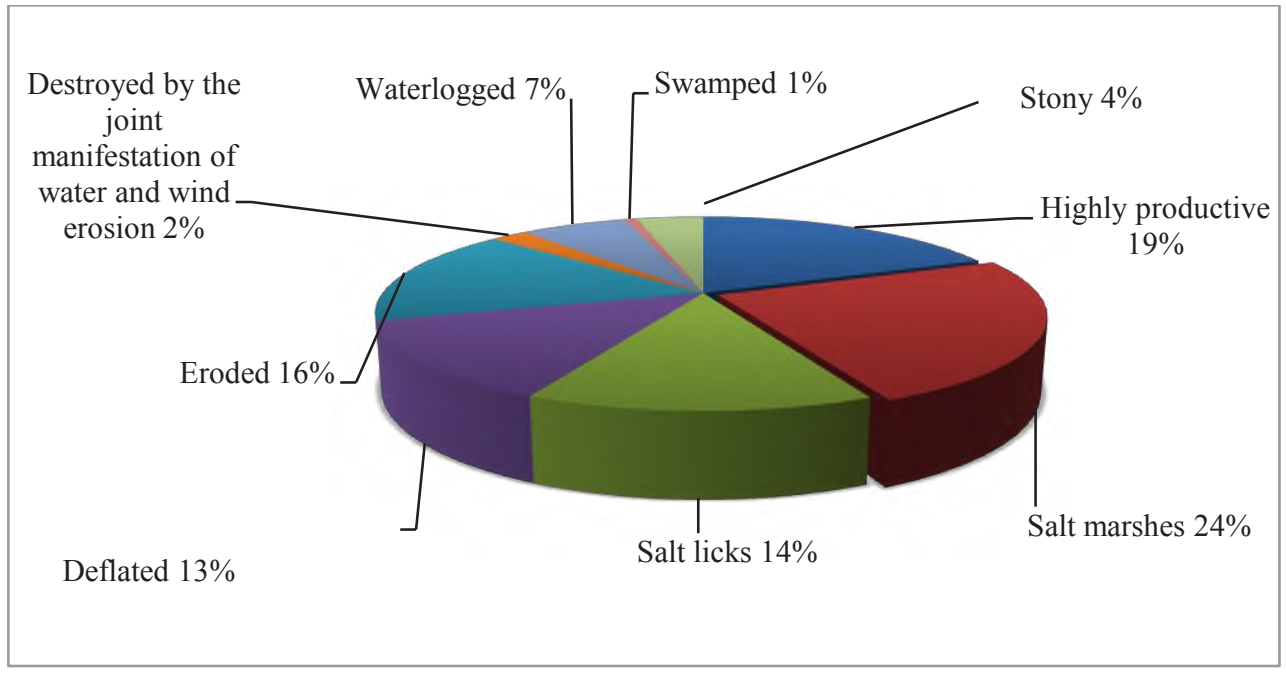

Fig. 1. Soil quality of agricultural land in the Stavropol Region.

Characteristic feature of the region is that the proportion of winds from the southern and northern directions is insignificant (Table 1). Therefore, there is no inflow of heat from the south and cold rains from the north. In half of the cases, east-west winds prevail. They initiate dust storms in the eastern regions of the region.

Table 1. Average wind rose based on the results of observations of meteorological stations in the Stavropol Region.

\begin{tabular}{|c|c|c|c|c|c|c|c|c|}
\hline $\begin{array}{c}\text { Direction of the } \\
\text { wind }\end{array}$ & N & N-E & E & S-E & S & S-W & W & N-W \\
\hline Probability. \% & 7.8 & 7.5 & 28.0 & 18.3 & 3.7 & 2.1 & 21.0 & 11.6 \\
\hline
\end{tabular}

It is enough to analyze the given data of Tables 1 , to superimpose the map of precipitation on the map of the wind rose, and it is possible to obtain, in the appropriate approximation, a map of soil degradation in the Stavropol Territory [14, 15]. In addition to drought, alkalinization, salinization, desertification, dehumification, flooding, the main causes of soil degradation are wind and water erosion. The obvious conclusion is that most of the territory of the Stavropol Region is subject to the combined effects of wind and water erosion. This gives two negative characteristics to agriculture. First, the erosional load on the soil becomes more prolonged in time, since surface washout occurs during rains, and deflation occurs during the dry season. Second, the damage from the joint manifestation of wind and water erosion is at least twice as large. Many years of experience in protecting soil from erosion in the Stavropol Territory has established that only $1 \mathrm{~mm}(2-3 \mathrm{t} / \mathrm{ha})$ of the fertile soil layer, lost as a result of erosion, is restored by the soil independently in the process of biological regeneration. With large losses, human intervention and long-term rehabilitation of the soil environment are necessary. The measures taken in this case can be preventive, compensatory and restorative.

Preventive measures are aimed at preventing the erosive effect of climatic factors on the soil or their significant reduction. Their action is assessed by professionals as the most effective. It is known that crops of perennial grasses best protect the soil from erosion. Compared to them, the damage to the soil on grain crops is 4-5 times greater, and on row crops - 24 times. Of course, this affects the yield: the average yield loss for all crops on all types of soils ranges from 20 to $40 \%$.

Compensatory protective measures are used to exclude or significantly reduce potential damage. Their purpose is as follows: if it is not possible to exclude crop losses from the 
loss of the fertile soil layer, then they must be compensated by eliminating other losses or acquiring new possibilities for preserving the harvest, for example, mineral fertilizers are used more widely. They cannot replenish soil fertility, but they are able to partially replace the metabolic functions of the soil environment. In recent years, the amount of applied per hectare (m) and the total volume of applied mineral fertilizers (S) has doubled and reached the value of $88 \mathrm{~kg}$ / ha and 228 thousand tons of active ingredient (a.i.), respectively (Figure 2 ). However, this is not enough, since the scientifically grounded need of the region is on average 410 thousand tons of diesel fuel.

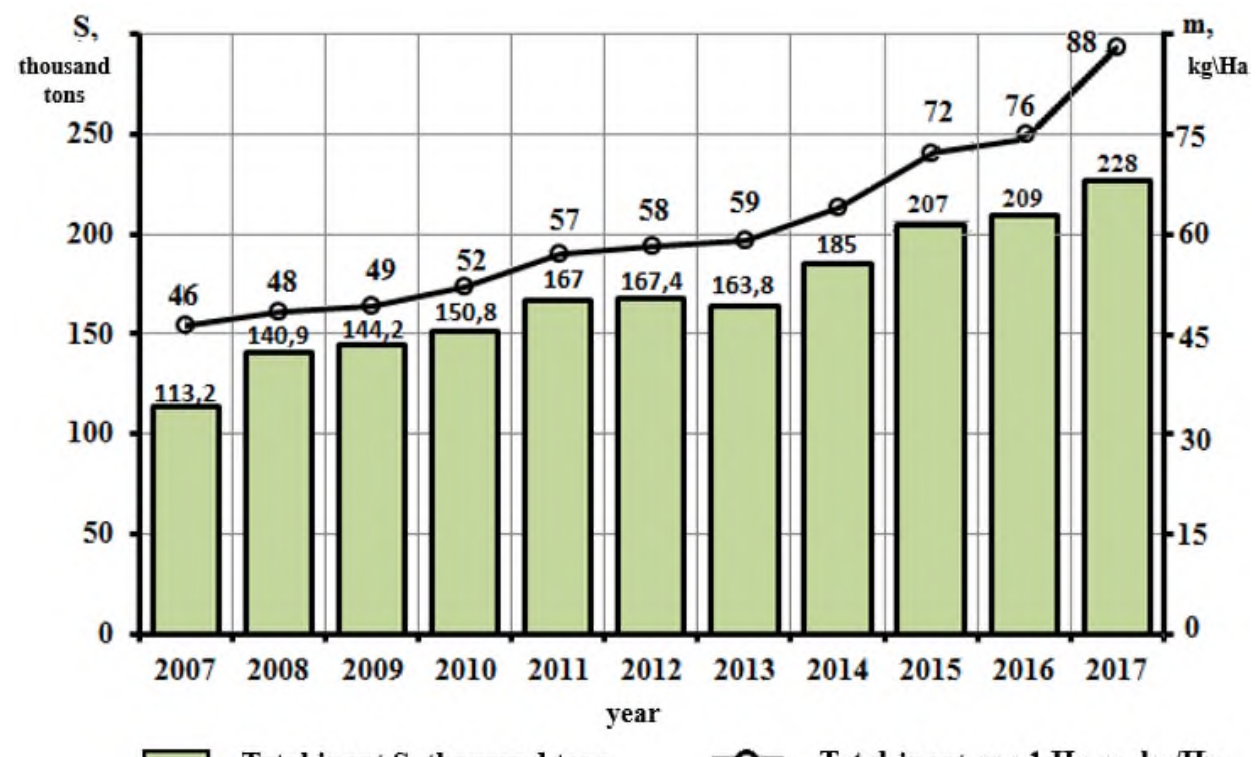

Fig. 2. Dynamics of the use of mineral fertilizers by agriculture in the Stavropol Region.

Another important indicator that is growing significantly every year is the consumption of chemical remedies. The Stavropol Territory belongs to the regions with a constantly high severity of pests, diseases, weeds. There are about 600 types of harmful objects. They reduce the yield of cultivated crops and reduce the quality of the products obtained. The increased consumption of chemical means of protection explains the significant reduction in crop losses in these areas. Thus, compensatory measures provide a high yield of crops on eroded soils with weakened fertility. However, they do not restore soil fertility and significantly increase the load of a wide range of chemicals on agricultural products and the human biological environment. This is a hidden, constantly accumulating negative result.

Restorative measures, in contrast to preventive and compensatory measures, are deeper and longer in time. They may include the removal of the restored land from the erosion load (for example, by transferring it to a fodder crop rotation, performing plantation plowing, increased application of organic fertilizers, etc.).

The technological arsenal of preventive, compensatory and recovery measures is wide enough, available and in demand by production. In cases of their application on time and in accordance with the recommendations, a noticeable effect is guaranteed. But with the joint manifestation of water and wind erosion, the result is ambiguous. Table 2 presents the main non-feasible rules for the application of soil protection technologies and the organization of the territory in cases of resistance to water and wind erosion. 
Table 2. Technological principles of soil protection against erosion.

\begin{tabular}{|c|c|}
\hline Water erosion & Wind erosion \\
\hline Cross-slope processing (horizontally) & Processing across the prevailing wind direction \\
\hline Protected field surface & Protected field surface \\
\hline Active cutting of the productive horizon & Minimum processing \\
\hline
\end{tabular}

Table 2 shows that the only common thing in approaches to soil protection from two types of erosion is the creation of a protected surface (mulching, leaving stubble behind the curtain). Tilling the soil across the direction of the prevailing winds only in half of the cases corresponds to cultivation and across the slope as well. The nature of the mechanical effect on soil cultivation in both cases has nothing in common and therefore there is no universal approach with a highly effective result: a positive result in counteracting one type of erosion does not mean an effect on the other. This is another feature of agriculture under conditions of joint manifestation of water and wind erosion, which has not yet been resolved in the modern farming system of the Stavropol Region.

\section{Conclusions}

Summing up, we note that the analysis and the problems noted, the identified aspects of the influence of various soil cultivation technologies on the state of soil fertility and the ways of their implementation, as well as the need to develop methods for combating water and wind erosion that are appropriate for regional conditions are only a small part of the tasks that require solutions through scientific research. So, the priority tasks can be based on the following conclusions:

1. Comprehensive mathematical model of agriculture seems to be in demand, which makes it possible to build promising, crisis and other options for the development of the system that are necessary in the future or according to the situation.

2. The farming systems of the Stavropol Territory are in constant development, they work under conditions of joint manifestation of water and wind erosion and so far cannot cope with the degradation of a third of the arable land of the Territory due to erosion processes.

3. Within the framework of the adaptive landscape farming system of the Stavropol Territory, there is no universal soil protection system of agriculture that would be equally effective in protecting soil from both water and wind soil erosion.

\section{References}

1. B. Autret, H. Guillier, V. Pouteau, B. Mary, C. Chenu, Soil and Tillage Research 204, 104712 (2020)

2. C.I. Calderón, C. Jerónimo, A. Praun, R. Hogan, J.P. Prado Córdova, Agroecology and Sustainable Food Systems 42(10), 1128-1169 (2018)

3. F. Bareille, P. Dupraz, Environmental and Resource Economics 77(2), 365-399 (2020)

4. R. Dagar, S. Som, S.K. Khatri, Proceedings of the International Conference on Inventive Research in Computing Applications, ICIRCA 8597264, 1052-1056 (2018)

5. T.A.A. Ali, V. Choksi, M.B. Potdar, Proceedings of the 2nd International Conference on Trends in Electronics and Informatics, ICOEI 8553866, 481-487 (2018)

6. Y. He, H. Liang, K. Hu, H. Wang, L. Hou, Agricultural Water Management 210, 316323 (2018)

7. G. Castelli, E. Bresci, F. Castelli, E.Y. Hagos, A. Mehari, Agricultural Water 
Management 210, 286-295 (2018)

8. J.A. Aguilar, V. Andreu, J. Campo, Y. Picó, A. Masiá, Science of the Total Environment 607-608, 752-760 (2017)

9. Y. Wang, C. Li, C. Tu, J.L. DeForest, S. Hu, Science of the Total Environment 609, 341-347 (2017)

10. R.K. Yadav, T.J. Purakayastha, M.A. Khan, S.C. Kaushik, Science of the Total Environment 609, 1535-1543 (2017)

11. S. Ghai, A. Sharma, P. Dasgupta, Journal of Community Health 29(4), 340-349 (2017)

12. T. Li, Y. Lü, B. Fu, P. Harris, L. Wu, Science of the Total Environment 607-608, 911919 (2017)

13. L. Halada, S. David, J. Hreško, M. Bural', L. Vadel, Science of the Total Environment 609, 896-905 (2017)

14. M.A. Aduov, S.N. Kapov, S.A. Nukusheva, M.R. Rakhimzhanov, Life Sci J 11(5s), 67-71 (2014) ISSN: http://www.lifesciencesite. com. 30

15. S.N. Kapov, M.A. Aduov, S.A. Nukusheva, Life Sci J 11(12s), 156-161 (2014) ISSN: http://www.lifesciencesite.com. 30 